\title{
PREVALENSI DISMENORE PADA REMAJA PUTRI DI MADRASAH ALIYAH DARUL ULUM DAN MIFTAHUL JANNAH PALANGKA RAYA
}

\author{
Aida Kusnaningsih \\ Staf Pengajar Poltekkes Kemenkes Palangka Raya \\ E-mail Aidaparyanto@yahoo.co.id
}

\begin{abstract}
Abstrak
Dismenore merupakan nyeri sebelum atau selama menstruasi, terjadi pada hari pertama sampai beberapa hari masa menstruasi. Kondisi ini mengakibatkan remaja putri mengalami kesulitan berkonsetrasi saat belajar dan ketidakhadiran pada proses belajar mengajar di kelas. Desain penelitian merupakan penelitian desktiptif kuantitatif. Sampel penelitian adalah siswi (remaja putri) di Madrasah Aliyah Darul Ulum dan Miftahul Jannah Palangka Raya berjumlah 160 orang, dengan teknik pengambilan sampel secara purposive sampling. Kuesioner yang digunakan yaitu pertanyaan/pernyataan yang berisi usia menarche, kejadian dismenore, riwayat keluarga dengan nyeri haid. Data dianalisis secara univariat dengan uji distibusi frekuensi.Penelitian mendapatkan hasil yaitu dari 160 responden didapatkan rerata usia menarche yaitu 12,89 tahun dengan standar deviasi 1,24, usia menarche terendah 9 tahun, dan tertinggi 17 tahun, mempunyai riwayat dismenore di keluarga 110 orang (69\%), dan mengalami nyeri haid 138 orang (86\%). Penelitian ini menyimpulkan bahwa sebagian besar responden mengalami nyeri haid, dan mempunyai riwayat keluarga dengan dismenore, serta rentang usia menarche 9-17 tahun dengan rerata 12,89 tahun.
\end{abstract}

Kata Kunci: Nyeri Haid, Dismenore, Angka Kejadian

\begin{abstract}
Dysmenorrhea is pain before or during menstruation, occurring on the first day to several days of menstruation. This condition results in young women having difficulty concentrating while studying and absence in the teaching and learning process in class. The research design is quantitative descriptive research. The sample of the study were 160 female students in Madrasah Aliyah Darul Ulum and Miftahul Jannah Palangka Raya, with purposive sampling technique. The questionnaire used was a question / statement containing the age of menarche, the incidence of dysmenorrhea, family history of menstrual pain. Data were analyzed univariately by frequency distribution test. The study found results from 160 respondents found the average age of menarche is 12.89 years with a standard deviation of 1.24 , the lowest age of menarche is 9 years, and the highest is 17 years, has a history of dysmenorrhea in a family of 110 people $(69 \%)$, and has menstrual pain 138 people $(86 \%)$. This study concluded that the majority of respondents experienced menstrual pain, and had a family history of dysmenorrhea, and the age range of menarche 9-17 years with an average of 12.89 years.
\end{abstract}

Keywords: Menstrual Pain, Dysmenorrhea, Incidence Rate 


\section{Pendahuluan}

Remaja merupakan masa transisi dari anak-anak menjadi dewasa, dalam rentang usia 10-19 tahun. Masa remaja atau masa pubertas merupakan masa yang sangat penting karena terjadinya pematangan organ-organ fisik (seksual), perubahan hormonal, psikologis maupun sosial. Salah satu tanda pubertas pada remaja putri yaitu terjadinya menstruasi [1].

Menstruasi merupakan perdarahan sebagai tanda bahwa organ reproduksi telah berfungsi matang [2]. Menstruasi adalah pendarahan rahim yang Sifatnya fisiologik (normal) yang datangnya teratur setiap bulan (siklus haid). Menstruasi pertama (menarche) berkisar pada usia 9 tahun hingga 16 tahun, berulang setiap 22-35 hari dengan rata-rata 3-7 hari, usia menarche [3].

\section{Selama menstruasi beberapa} masalah dapat terjadi diantaranya adalah nyeri haid (dismenore). Nyeri Haid (Dismenore) merupakan keluhan ginekologis akibat ketidakseimbangan hormon progesteron dalam darah sehingga mengakibatkan timbulnya rasa nyeri yang paling sering terjadi pada wanita [4]. Dismenore adalah nyeri sebelum atau selama menstruasi, terjadi pada hari pertama sampai beberapa hari masa menstruasi [5].

Penelitian menunjukkan bahwa kejadian dismenore cukup tinggi. Penelitian Refrensi [6] menunjukkan pada 404 anak perempuan dari dua sekolah menengah negeri di wilayah Muscat Oman didapatkan hasil 380 orang (94\%) mengalami dismenorea. Penelitian Refrensi [7] pada 1515 mahasiswa Turki didapatkan hasil 85,7\% mengalami dismenore. Penelitian Refrensi [8] pada 356 Mahasiswa di Universitas Islam Mohiuddin, Mirpur Azad Kashmir didapatkan hasil 56,1\% mengalami dismenore.

Kejadian dismenore primer di Indonesia mencapai 54,89\%, sedangkan dismenorea sekunder sebanyak 45,11\% [9]. Penelitian Refrensi [10] didapatkan hasil dismenore primer pada remaja wanita usia 14-19 tahun di Indonesia sekitar 54,89\%.

Dismenore dapat disebabkan oleh berbagai faktor. Dismenore disebabkan oleh kelebihan hormone prostaglandin pada jaringan endometrium [5]. Penelitian menunjukkan faktor-faktor yang berhubungan dengan kejadian dismenore yaitu lama menstruasi, tingkat stress, aktivitas olahraga, anemia, riwayat keluarga, status gizi, Asupan Makanan dan Kurang tidur [11], [12], [13], [14]

Penelitian menunjukkan bahwa usia menarche dan riwayat dismenore di keluarga berhubungan dengan kejadian dismenore. Penelitian yang dilakukan Refrensi [15] yang dilaksanakan di lembaga publik pendidikan tinggi Fakultas Ilmu Kedokteran, Universitas Kragujevac Serbia menunjukkan ada hubungan riwayat 
keluarga dengan dismenorea $(\mathrm{p}=0.000)$. Penelitian oleh Refrensi [16] pada siswa SMAN 2 Bagan Sinembah Kabupaten Rokan Hilir didapatkan hasil riwayat keluarga berhubungan dengan dismenore $(p=0,000)$.

Dismenore dapat memberikan berbagai dampak yang kurang baik bagi remaja putri. Penelitian yang dilakukan Refrensi [17] pada 140 mahasiswa, sebagian besar $(68,4 \%)$ aktivitas belajar terganggu akibat dismenore. Dampak yang paling banyak dirasakan karena dismenore adalah keterbatasan aktivitas fisik, isolasi sosial, konsentrasi yang buruk, dan ketidakhadiran dalam proses belajar mengajar [18]. Penelitian Refrensi [18] pada 440 Pelajar Wanita di Ethiopia, dampak dismenore yaitu absen di sekolah (80\%), kehilangan konsentrasi di sekolah $(66,8 \%)$,ketidakhadiran di kelas $(56,3 \%)$, ketidakmampuan untuk pekerjaan rumah (21\%), keterbatasan dalam aktivitas olahraga $(37,8 \%)$, keterbatasan untuk keluar dengan teman $(31,7 \%)$.

Kondisi tersebut menunjukkan bahwa dismenore merupakan suatu masalah yang memerlukan penanganan secara baik dan komprehensif. Untuk itu sangat diperlukan data yang mendukung seberapa besar suatu masalah tersebut terjadi. Studi pendahuluan yang dilakukan di Madrasah Aliyah Darul Ulum dan Miftahul Jannah Palangka Raya didapatkan hasil bahwa belum pernah dilakukan penelitian mengenai kejadian dismenore. Hasil wawancara dengan 10 orang siswa didapatkan hasil 7 orang mengalami dismenore. Sehingga penelitian ini bertujuan untuk mengetahui gambaran kejadian dismenore di Madrasah Aliyah Darul Ulum dan Miftahul Jannah Palangka Raya.

\section{Metode}

Desain penelitian merupakan penelitian desktiptif kuantitatif. Sampel penelitian adalah siswi (remaja putri) di Madrasah Aliyah Darul Ulum dan Miftahul Jannah Palangka Raya berjumlah 160 orang, dengan teknik pengambilan sampel secara consecutive sampling. Kuesioner yang digunakan yaitu pertanyaan/ pernyataan yang berisi usia menarche, kejadian dismenore, riwayat keluarga dengan nyeri haid. Data dianalisis secara univariat dengan uji distibusi frekuensi.

\section{Hasil dan Pembahasan}

Hasil penelitian yang telah dilakukan dapat dilihat pada table-tabel di bawah ini:

Tabel 1

Gambaran Rerata Usia Menarche Pada Remaja Putri Di MA Darul Ulum dan Miftahul Jannah Palangka Raya $(n=160)$

\begin{tabular}{cccccc}
\hline Variabel & Mean & $\begin{array}{c}\text { Standar } \\
\text { Deviasi }\end{array}$ & Min & Mak & $95 \% \mathrm{Cl}$ \\
\hline $\begin{array}{c}\text { Usia } \\
\begin{array}{c}\text { Menarche } \\
\text { (tahun) }\end{array}\end{array}$ & 12,89 & 1,24 & 9 & 17 & $\begin{array}{c}12,69- \\
13,08\end{array}$ \\
\hline
\end{tabular}

Tabel 1 menunjukkan bahwa Rerata Usia Menarche Pada Remaja Putri Di MA Darul Ulum dan Miftahul Jannah Palangka Raya yaitu 12,89 tahun dengan standar deviasi 
1,24. Usia menarche terendah yaitu 9 tahun dan usia menarche tertinggi yaitu 17 tahun.

Tabel 2

Distribusi Frekuensi Riwayat Keluarga

Remaja Putri Di MA Darul Ulum dan Miftahul Jannah Palangka Raya $(n=160)$

\begin{tabular}{lcc}
\hline $\begin{array}{c}\text { Riwayat Keluarga } \\
\text { Nyeri Haid }\end{array}$ & $\begin{array}{c}\text { Frekuensi } \\
\text { (n) }\end{array}$ & $\begin{array}{c}\text { Persentase } \\
\text { (\%) }\end{array}$ \\
\hline Ada Riwayat & 110 & 69 \\
Tidak Ada Riwayat & 50 & 31 \\
\hline
\end{tabular}

Tabel 2 menunjukkan bahwa dari 160 orang remaja putri sebagian besar mempunyai riwayat dismenore di keluarga (69\%).

Tabel 3

Distribusi Frekuensi Kejadian Dismenore

Remaja Putri Di MA Darul Ulum dan

Miftahul Jannah Palangka Raya $(n=160)$

\begin{tabular}{ccc}
\hline $\begin{array}{c}\text { Kejadian } \\
\text { Dismenore }\end{array}$ & $\begin{array}{c}\text { Frekuensi } \\
(\mathbf{n})\end{array}$ & $\begin{array}{c}\text { Persentase } \\
\text { (\%) }\end{array}$ \\
\hline Ada Nyeri Haid & 138 & 86 \\
Tidak Nyeri Haid & 22 & 14 \\
\hline
\end{tabular}

Tabel 3 menunjukkan bahwa dari 160 orang remaja putri sebagian besar mengalami nyeri haid 138 orang (86\%)

Penelitian ini mendapatkan hasil bahwa sebagian besar (86\%) remaja mengalami mengalami nyeri haid. Hasil penelitian ini sejalan dan mendukung beberapa penelitian yang telah dilakukan. Penelitian yang dilakukan oleh Refrensi [19] pada remaja putri rentang usia 12-13 tahun didapatkan hasil 63 responden (81\%) mengalami dismenore. Penelitian yang dilakukan Refrensi [20] pada siswi SMPN 3 Manado didapatkan hasil 199 orang (98,5\%) mengalami dismenore.

$$
\text { Penelitian Refrensi }
$$

menunjukkan pada remaja Hispanik dari 706 orang, 85\% mengalami dismenore. Penelitian Refrensi [22] menunjukkan pada 165 remaja Taiwan $87,3 \%$ mengalami dismenore. Chen \& Lin (2010) pada 616 remaja Taiwan 570 orang $(92,5 \%)$ mengalami dismenore. Penelitian oleh Refrensi [3] pada remaja di Accra Ghana dari 453 orang, $74,4 \%$ mengalami dismenore.

Penelitian Refrensi [23] pada 344 siswa sekolah menengah di Saudi Arabia Utara didapatkan hasil 256 (74,4\%) mengalami dismenore. Penelitian yang dilakukan oleh Refrensi [24] pada mahasiswa di Universitas Northern Ghana didapatkan hasil 245 (83,6\%) dari 293 responden mengalami dismenore. Penelitian Refrensi [25] pada 2.555 anak perempuan di China didapatkan hasil 1306 mengalami dismenore.

Dismenore berhubungan dengan usia menarche dan riwayat dismenore di keluarga. Menarche adalah periode menstruasi yang pertama terjadi pada masa pubertas seorang anak perempuan biasanya terjadi pada usia 10-16 tahun, faktor seperti keturunan dan kesehatan berpengaruh terhadap cepat atau lambatnya awal haid [26]. Menarche atau menstruasi pertama umumnya dialami remaja pada usia 13-14 tahun. 
Menarch merupakan tanda dari pematangan fisik organ reproduksi wanita. Terlalu dini usia menarche merupakan faktor resiko penting dari dismenore primer. Hal ini didasari terlalu dini usia menarche, memungkinkan keterpaparan yang lebih lama terhadap prostaglandin yang dihasilkan oleh endometrium saat menstruasi [18]. Menache yang terjadi lebih awal akan menimbulkan rasa sakit ketika menstruasi karena alat reproduksi belum siap untuk mengalami perubahan dan masih terjadi penyempitan pada leher rahim [27].

Menarche yang makin dini memungkinkan anak perempuan lebih cepat bersentuhan dengan kehidupan seksual sehingga kemungkinan remaja untuk hamil dan menjadi seorang ibu semakin besar. Selain itu menarche dini dapat menimbulkan risiko berbagai penyakit di masa dewasa, misalnya, menarche dini mungkin terkait dengan obesitas, penyakit kardiovaskular, atau kanker.

Penelitian ini mendapatkan bahwa rerata usia menarche remaja putri adalah 12,89 tahun dengan usia terendah 9 tahun dan usia tertinggi 17 tahun. Hasil penelitian ini sejalan penelitian oleh Refrensi [28] pada siswi 21 orang siswa di SMKN Malang yang terbagi dalam 3 kelompok yaitu kelompok kontrol, kelompok Eksperimen I dan Kelompok Eksperimen II di dapatkan hasil usia menarche yaitu pada kelompok kontrol dan kelompok eksperimental I paling sebagian besar pada rentang usia 13-15 tahun, sedangkan pada kelompok eksperimental II sebagian besar pada rentang usia 10-12 tahun. Penelitian yang dilakukan oleh Refrensi [29] yang menyatakan bahwa usia responden yang mengalami usia menarch paling banyak yaitu usia $<12$ tahun. Usia menarche antara 9-16 tahun, dengan rata-rata 12,5 tahun [3]. Dismenore primer umumnya terjadi 2-3 tahun setelah menarche, dan puncaknya pada usia 20 tahun dan akan menurun seiring bertambahnya usia [30].

Penelitian ini juga mendapatkan hasil bahwa 160 orang remaja putri sebagian besar mempunyai riwayat dismenore di keluarga (69\%). Menurut Refrensi [27], adanya riwayat keluarga dan genetic berkaitan dengan terjadinya dismenore primer yang berat. Refrensi [31] menyatakan dalam penelitiannya yang menjadi faktor terjadinya dismenore adalah adanya riwayat keluarga yang mengalami dismenore. Penelitian Refrensi [23], pada 344 siswa sekolah menengah di Saudi Arabia Utara didapatkan $65,7 \%$ ada riwayat keluarga dengan dismenore. Penelitian Refrensi [33] pada 4140 remaja, 53,7\% mempunyai riwayat dismenore di keluarga.

\section{Kesimpulan}

1. Rerata Usia Menarche Pada Remaja Putri Di MA Darul Ulum dan Miftahul Jannah Palangka Raya yaitu 12,89 tahun dengan standar deviasi 1,24. Usia menarche terendah yaitu 9 tahun dan usia menarche tertinggi yaitu 17 tahun.

2. Riwayat dismenore di keluarga yaitu 160 orang remaja putri sebagian besar 
mempunyai riwayat dismenore di keluarga (69\%).

3. Kejadian dismenore pada remaja putri yaitu dari 160 orang 138 orang (86\%) mengalami nyeri haid.

\section{DAFTAR PUSTAKA}

1. Batubara, J. RL. (2012). Adolescent Development (Perkembangan Remaja. Sari Pediatri, 12(1), 21-29.

2. Kusmiran, E. (2012). Kesehatan Reproduksi Remaja dan Wanita. Jakarta: Salemba Medika.

3. Gumanga, S. K. dan Kwame-Aryee, R. A. (2012). Menstrual characteristics in some adolescent girls in Accra, Ghana. Ghana Medical Journal. 46(1).3-7

4. Prayitno, S. (2014). Buku Lengkap Kesehatan Organ Reproduksi Wanita. Yogyakarta: Saufa.

5. Afiyanti, Y., \& Pratiwi, A. (2016). Seksualitas dan Kesehatan Reproduksi Perempuan. Jakarta: Rajawali Pers Raja Grafindo Persada.

6. Al-Kindi, R. dan Al-Bulushi, A. (2011). Prevalence and Impact of Dysmenorrhoea among Omani High School Students. Sultan Qaboos University Medical Journal, 11(4). 485-491.

7. Potur, D.C., Bilgin, N. C., dan Komurcu, N. (2014). Prevalence of dysmenorrhea in university students in Turkey: effect on daily activities and evaluation of different pain management methods. Pain Manag Nurs. 15(4):768-77. doi: 10.1016/j.pmn.2013.07.012.
8. Yasir, S., Kant, B., dan Dar, M. F. (2014). Frequency of dysmenorrhoea, its impact and Management strategies adopted by medical students. J Ayub Med Coll Abbottabad. 26(3).349-352.

9. Proverawati, A., \& Misaroh, S. (2009). Menarche: Menstruasi pertama penuh makna. Yogyakarta: Nuha Medika.

10. Mahmudiono, T. (2011). Fiber, PUFA and Calcium Intake is Associated With The Degree of Primary Dysmenorrhea in Adolescent Girl Surabaya, Indonesia. Journal Obstetrics \& Gynecology.

11. Hadikasari, C., A., A. (2015). Hubungan anemia, status gizi, olahraga dan pengetahuan dengan kejadian dismenore pada remaja putri. Midwiferia. 1(1). 31-43.

12. Gagua, T., Tkeshelashvili, B., \& Gagua, D. (2012). Primary dysmenorrhea: prevalence in adolescent population of Tbilisi, Georgia and risk factor. $J$ Turkish-German Gynecol Assoc; 13: 162-8. doi: 10.5152/jtgga.2012.21

13. Pundati, T. M., Sistiarani, C. \& Hariyadi, B. (2016). Faktor-faktor yang berhubungan dengan kejadian dismenore pada mahasiswa semester VIII universitas jenderal soedirman purwokerto, Jurnal Kesehatan Masyarakat, 8(1).40-48.

14. Ramadani, A. N. (2014). Hubungan Kebiasaan Olahraga dengan Kejadian Dismenore pada Siswi di SMPN 2 Demak. Retrieved from: https://docplayer.info/30730383Hubung an-kebiasaan-olahraga-dengan- 
kejadian-dismenore-pada-siswi-di-smp-

n-2-demak-tahun-2014.html

15. Pejc'ic, A., \& Jankovic', S. (2016). Risk Factors for Dysmenorrhea Among Young Adult Female University Students, 52(1), 98-103. https://doi.org/10.4415/ANN

16. Juliana. (2018). Determinan dismenorea di sman 2 bagan sinembah kabupaten rokan hilir. Jurnal Endurance, 3(1). 61-68.

17. Iswari, D. P. (2014). Hubungan dismenore dengan aktivitas belajar mahasiswi PSIK FK UNUD. Jurnal Keperawatan FK UNUD. 2(3). ISSN 2303-1298.

18. Hailemeskel, S., Demissie, D., \& Assefa, N. (2016). Primary dysmenorrhea magnitude, associated risk factors, and its effect on academic performance: evidence from female university students in ethiopia. International Journal Womens Health. Dovepress. 8.489-496. doi: $10.2147 / / J W H . S 112768$

19. Astuti, E. P. \& Noranita, L. (2016). Prevalensi kejadian gangguan menstruasi berdasarkan indeks masa tubuh (IMT) pada siswa kelas VII SMP. Journal IImu Kebidanan 1(3), 58-64.

20. Lestari, H., Metusala, J., \& Suryanto, D. Y. (2010). Gambaran dismenore pada remaja putri sekolah menengah pertama di Manado, Sari Pediatri, 12(2).99-102

21. Banikarim, C., Chacko, M. R., \& Kelder, S.H. (2000). Prevalence and impact of dysmenorrhea on Hispanic female adolescents. Arch Pediatr Adolesc Med.154(12).1226-1229

doi:10.1001/archpedi.154.12.1226

22. Lu, I-Chen. (2010). Dysmenorrhea and related factors in Taiwanese adolescent girls. The Dissertation. Retrieved from: https://repositories.

lib.utexas.edu/bitstream/handle/2152/E

TD-UT-2010-05-1198/LU-

DISSERTATION.pdf?sequence=1\&isAll owed $=\mathrm{y}$.

23. Abd El-Mawgod, M. M., Alshaibany, A.S., \& Al-Anazi, A.M. (2016). Epidemiology of dysmenorrhea among secondary-school students in Northern Saudi Arabia. J Egypt Public Health Assoc. 91(3), 115-119.

24. Ameade, E. P. K., Amalba. A. and Mohammed, B. S. (2018). Prevalence of dysmenorrhea among University students in Northern Ghana; its impact and management strategies. $B M C$ Women's Health. 18(39).1-9. https://doi.org/10.1186/s12905-0180532-1.

25. Chen L, Tang L, Guo S, et al. (2019) Primary dysmenorrhea and self-care strategies among Chinese college girls: a cross- sectional study. BMJ Open. 19 doi: 10.1136/bmjopen-2018-026813.

26. Zulaikha, F. L. F. (2010). Hubungan Pengetahuan Kesehatan Reproduksiremaja Putrid Terhadap Sikap Menghadapi Premenstruasi Syndrome Di SMA 5 Surakarta. Karya Tulis IImiah. Universitas Sebelas Maret. 
Prevalensi Dísmenore Pada Remaja Putri Di Madrasah Aliyah

DaruC Ulum Dan Miftahul Jannah Palangka Raya

27. Widjanarko, B. (2006). Tinjauan Terapi Pada Dismenore Primer. Majalah Kedokteran Damianus. Vol.5. No.1 Januari

28. Febriani, D., Ariani, D., dan Kusumastuty, I. (2018). Pengaruh Konsumsi Susu Sapi Terhadap Penurunan Intensitas Nyeri Dismenore Primer Pada Siswi Jurusan Keperawatan di SMKN 2 Malang. Journal of Issues in Midwifery. 2(2).2033.

29. Gustina, Tina. 2015. Hubungan Antara Usia Menarche Dan Lama Menstruasi Dengan Kejadian Dismenore Primer Pada Remaja Putri Di SMKN 4 Surakarta. Retrieved from http://eprints.ums.ac.id/38652/17/NASK AH\%20PUBLIKASI.oke.tina.pdf

30. Kural, M., Noor, N. N., Pandit, D., Joshi, T., Patil, A. (2015). Menstrual Characteristics And Prevalence Of Dysmenorrhea In College Going Girls. $J$ Family Med Prim Care. 4(3). 426431. doi: $10.4103 / 2249-4863.161345$

31. Utami, A. N., Ansar, J., \& Sidik, D. Faktor yang berhubungan dengan kejadian dismenorea pada remaja putri
SMAN1 Kahu Kabupaten Bone.

Retrieved

from:http://repository.unhas.ac.id/bitstre am/handle/123456789/5523/jurnal.pdf;s equence $=1$

32. De Sanctis, V., Soliman, A.T., Elsedfy, H., Soliman, N. A., Soliman, R., dan El Kholy, M. (2017. Dysmenorrhea in adolescents and young adults: a review in different country. Acta Biomed. 87(3):233-246. 